EGG-I:- -09082

DE82 017742

ACTINIDE INTEGRAL MEASUREMENTS IN THE CFRMF

AND INTEGRAL TESTS FOR ENDF/B-V

by

R. A. Ander 1

EG\&G Idaho Inc.

Idaho National Engineering Laboratory

Idaho Falls, Idaho 83415

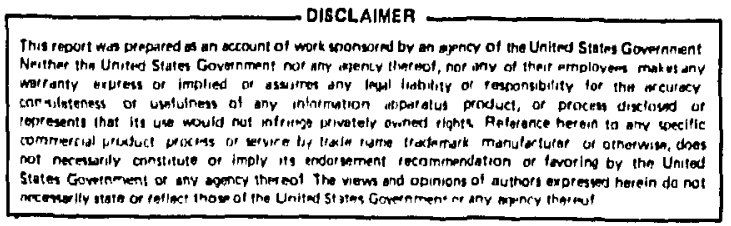

To be published in the proceedings of the

MEANDC/NEACRP Specialists Meeting on Fast-Neutron

Capture Cross Sections

Argonne National Laboratory

April 20-23, 1982 


\title{
ACTINIDE INTEGRAL MEASUREMENTS IN THE CFRMF AND INTEGRAL TESTS FOR ENDF/B-V*
}

\author{
by
}

R. A. Ander 1, Y. D. Harker, J W Rogers EG\&G Idaho, Inc.

Idaho National Engineering Laboratory

Idaho Falls, Idaho 83415

\begin{abstract}
Integral capture and/or fission rates have been reported earlier for several actinides irradiated in the fast neutron field of the Coupled Fast Reactivity Measurements Facility (CFRMF). These nuclides include $232 \mathrm{Th}, 233 \mathrm{U}, 235 \mathrm{U}, 238 \mathrm{U}, 237 \mathrm{~Np}$, $239 \mathrm{Pu}, 240 \mathrm{Pu}, 242 \mathrm{Pu}, 24 \mathrm{Am}$ and $243 \mathrm{Am}$. This paper focuses on the utilization of these integral data for testing the respective cross sections on ENDF/B-V. Integral cross sections derived from the measured reaction rates are tabulated. Results are presented for cross-section data testing which includes integral testing based on a comparison of calculated and measured integral cross sections and testing based on least-squares-adjustment analyses.
\end{abstract}

\section{Introduction}

Integral reaction rates have been measured for several actinides irradiated in the fast neutron field of the Coupled Fast Reactivity Measurements Facility (CFRMF) ${ }^{1,2}$. The purpose of this paper is to summarize this integral data base and to present the results of using these integral data to test the respective cross sections on ENDF/B-V. The impact of this work on the radiative neutron capture reactions is highlighted. Section II of this paper includes a brief deccription of the CFRMF, an identification of the types of integral measurements and a tabulation of integral cross sections derived from the measured reaction rates. The utilization of the measured integral data for testing the respective cross sections on ENDF/B- $V$ is covered in Section III. Both conventional integral testing based on a comparison of

* Work supported by the US Department of Energy under DOE contract No. DE-ACO7-76ID01570. 
calculated-to-measured integral cross sections and testing based on leastsquares-adjusiment analyses are used to assess the consistency between the measured integral data and the evaluated cross sections. Conclusions drawn from this work are presented in Section IV.

\section{Integral Data Ease}

The irradiation facility for the actinide integral measurements is the CFRMFi,2 which is a zoned-core critical assembly with a fast neut i un spectrum zone in the center of an enriched $235 \mathrm{U}$, water moderated thermal driver. Approximately $95 \%$ of the neutrons in the central spectrum are between $4 \mathrm{keV}$ and $4 \mathrm{MeV}$ and the median and mean neutron energies are $370 \mathrm{keV}$ and $1760 \mathrm{keV}$, respectively. The central neutron spectruin is a cross-Section Evaluation Working Group (CSEWG) benchmark field for testing dosimetry, fission-product and actinide cross sections for ENDF/B-V. An update of the CFRMF central neutron spectrum characterization has been reported recent $7 y^{3,4}$.

A variety of techniques have been used for the integral measurements. Fission rates based on absolute fission chamber (FC) measurements have been reported by Grundl et. al $1^{5}$ for $235 \mathrm{U}, 238 \mathrm{U}, 237 \mathrm{~Np}$ and $239 \mathrm{Pu}$. Measurements of the fission rates of $232 \mathrm{Th}, 233 \mathrm{U}$ and $240 \mathrm{Pu}$ relative to the fission rate of $235 \mathrm{U}$ have been reported by Gilliam and Rogers ${ }^{6}$. Thes: latter experiments employed the NBS double fission chamber (DFC). The ganma spectrometric method ${ }^{7}$ was used in the determination of the fission rates for $232 \mathrm{Th}, 242 \mathrm{Pu}$, ${ }^{241} \mathrm{Am}$ and $243 \mathrm{Am}$ based on absolute measurements of the gamma emission rates of the prominent 1 ines in the ${ }^{140} \mathrm{Ba} .140 \mathrm{La}$ decay 8,910 . With the exception of the capture rate for $241 \mathrm{Am}$ which was determined using isotope-dilutionaipha spectrometry (IDAS) ${ }^{10}$, the capture rates for $232 \mathrm{Th}, 238 \mathrm{U}, 242 \mathrm{pu}$ and $243 \mathrm{Am}$ are based on gamma spectrometric measurements 7,10.' Many of the measurements were made as part of the Interlaboratory Reaction Rate (ILRR) Program l!

Spectrum-averaged cross sections were derived by dividing the measured integral reaction rates by absolute neutron fluxes which were determi ned for each measurement. The neutron flux determinations are based on the use of the ${ }^{197} \mathrm{Au}(n, \gamma) 198_{\mathrm{Au}}$ reaction as a power 1 evel monitor and on an independent determination of the neutron flux for one power level. The independent absolute flux value is based on a flux transfer ${ }^{12}$ using measured fission rates for ${ }^{239} \mathrm{Pu}$ in the CFRMF and in the National Bureau of Standards (NBS) ${ }^{252} \mathrm{Cf}$ standard field and on a measured integral cross section for $239 \mathrm{p}(n, f)$ in the 252 Cf field?

A tabulation of the "measured" integral cross sections is given in column 4 of Table 1. The value in parenthes is is the estimate of the total percent error in the integral cross section, at the one sigma confidence level. Columns 2 and 3 provide necessary identification of the experiment type and the reference for the integral reaction-rate measurements.

\section{Cross-Section Data Testing}

Integral tests of the evaluated capture and fission cross sections were made by comparing the "measured" integral cross sections to integral cross sections computed using 620-group representations of the CFRMF central spectrum $^{13}$ and of the differential data on ENDF/B-V. The calculated integral 
cross sections and the ratios of calculated-to-measured integral cross section are listed in columns 5 and 6 , respectively, of Table 1 . Two uncertainty values, expressed as percent, are 1 isted in parenthes is for the calculated integral cross sections. The first corresponds to the error in the calculated integral cross section due to spectrum uncertainties ${ }^{4}$ only. The second uncertainty contribution, wherever it is given, corresponds to the error in the calculated integral cross section due to cross-section uncertainties as processed from the ENDF/B-V uncertainty files. One uncertainty value, expressed as percent, is given for each $C / M$ ratio. That value corresponds to the quadrature sum of the error in the "measured" integral cross section and the error in the calculated integral cross section due to spectrum error contributions only.

For the radiative capture reactions, the integral test analys is indicates an inconsistency between the measured integral data and the ENDF/B-V

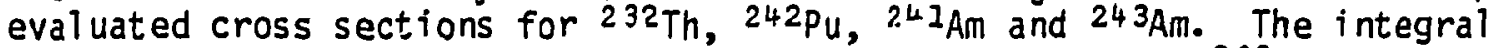
test indicates that the ENDF/B-V capture cross section for $238 \mathrm{U}$ is consistent with the measured integral data. Column 7 in Table 1 ists the ratio of the integral cross section computed with ENDF/B-V differential data to that computed with ENDF/B-IV differential data. This information indicates how the changes made to the capture cross section in yoing from ENDF/B-IV to ENDF/B-V impact the consistency test. The last two columns in Table 1 provide a qualitative indication of the response range for each reaction in the CFRMF spectrum. Response plots as a function of energy are given in Reforence 14 for these reactions.

Least-squares-adjustment analyses were made with the FERRET code ${ }^{15}$. The adjustment analys is was made in a 53-group energy structure and it included the following input data: (1) 23 dosimeter integral reaction rates ${ }^{3}$, (2) six integral reaction rates for capture and fission in $242 \mathrm{Pu},{ }^{241} \mathrm{Am}$, $243 \mathrm{Am},(3)$ CFRMF spectrum and associated covariance matrix, (4) cross sections processed with CFRMF spectrum weighting from ENDF/B-V for all reactions, and (4) covariance matrices for all reactions. The measured integral data were assumed to have zero correlation in the analyses. Covariance matrices for the dosimeter reactions were a mixture of matrices processed directiy from the ENDF/B-V covariance files and matrices generated by $F$. Schmittroth to improve upon the ENDF/B-V prescriptions 16 . Covariance matrices for the actinide reactions were generated by using a gaussian-type parametric form to describe the short-range correlations between the group wise uncertainties as obtained from ENDF/B- $V$ and adding an additional normalization uncertainty in the unresolved and smooth energy ranges. This approach was used because of the limitations of the error files on ENDF/B-V (no error files for $243 \mathrm{Am}$, missing error and correlation information for some energy regions for $241 \mathrm{Am}$ and $242 \mathrm{Pu}$, block-type correlation specifications.) The 241 Am uncertainty information on ENDF/B-V was used for $24^{3} \mathrm{Am}$, however, the normalization component was doubled from $15 \%$ for $241 \mathrm{Am}$ to $30 \%$ for $243 \mathrm{Am}$.

Preliminary results of the least-sguares-analys is are illustrated in Figures $1-3$ for the $232 \mathrm{Th}, 241 \mathrm{Am}$ and $243 \mathrm{Am}$ radiative capture cross sactions, The upper part of each figure shows a direct comparison of the 53-group cross sections over the neutron energy ranges in which the CFRMF spectrum is sensitive. The bottom part of each $f i j u r e$ shows the ratio of adjusted-to-unadjusted cross sections for the analysis. These figures indicate the energy range and the magnitude of the adjustments required to achieve consistency 
between the measured integral data and the evaluated cross sections. For $242 \mathrm{pu}(n, y)$, the input covariance specification was too tight to permit sufficient cross-section adjustment to achieve consistency between the measured integral data and the adjusted cross section.

\section{Conclusions}

In this paper we have summarized the actinide capture and fission integral data base for measurements in the fast neutron field of the CFRMF. An integral testing analysis in which the "measured" integral cross sections were compared to integral cross sections calculated with ENDF/B-V differential data indicaced that for the fast neutron radiative capture cross sections for $232 \mathrm{Th}, 242 \mathrm{Pu}, 241 \mathrm{Am}$ and $243 \mathrm{Am}$, the measured integral data are inconsistent with the evaluated cross sections. This same analys is indicated consistency between the measured integral data and the ENDF/B-V capture cross section for $238 \mathrm{U}$. A least-squares-adjustment analys is indicated that the following cross-section adjustments are required to resolve the discrepancies between the measured integral data and the ENDF/B-V capture evaluations: ${ }^{232} \mathrm{Th}(n, y), \tilde{5} 5 \%$ to $10 \%$ up (1 keV to $\left.17 \mathrm{MeV}\right) ; 24{ }^{1} \mathrm{Am}(n, y),-30 \%$ up (10.1 keV to $17 \mathrm{MeV}), 243 \mathrm{Am}(n, \gamma)-44 \%$ up $(0.1 \mathrm{keV}$ to $17 \mathrm{MeV})$. This assessment for $232 \mathrm{Th}$ is consistent with a recent measurement at 23-keV neutron energy by Baldwin and Knoll 17. The above assessment for the ${ }^{241} \mathrm{Am}$ and ${ }^{243} \mathrm{Am}$ capture reactions is contingent on an experimental verification of the neutroncapture branching fraction data used in the analysis of the integral experiments ${ }^{18}$. However, the assessinent of the $241_{A m}$ and $24{ }^{A m}$ ENDF/B-V capture cross sections is consistent with other information presented at this meeting 19,20 . Although the present work indicated a significant discrepancy between the measured integral data and the ENDF/B-V capture cross section for ${ }^{242} \mathrm{Pu}$, additional work is required to resolve questions concerning the accuracy of the measured integral data ${ }^{15}$.

\section{REFERENCES}

1. J W Rogers, D. A. Millsap and Y. D. Harker, Nucl. Tech. 25, 330 (1975).

2. J W Rogers, D. A. Mill sap and Y. D. Harker, "The Coupl ed Fast Reactivity Measurements Facility (CFRMF)," in Proc. of IAEA Consultants ileeting on Integral Cross-Section Measurements for Reactor Dosimetry, IAEA, Vienna, A.ustria, November 15-19, 1976, IAEA-208, Vol. II, 117 $(1976)$.

3. R. A. Anderl, Y. D. Harker, D. A. Millsap, JW Rogers and J. M. Ryskamp, "CFRMF Spectrum Update and Application to Dosimeter Cross-Section Data Testing," in the Proc. for the Fourth ASTM-EURATOM Symposium on Reactor Dosimetry, National Bureau of Standards, March 22-26, 1982.

4. J. M. Ryskamp, R. A. Anderl, 3. L. Broadhead, W. E. Ford III, J. L. Lucius, J. H. Maratie, and J. J. Wagschal, Nucl. Tech. 57, 20 (1982).

5. J. A. Grundl, et. al, Nuc. Tech 25, 237 (1975). 
6. D. M. G1111 am and J W Rogers, "Fission Cross-Section Ratios for U-233, Th-232, and Pu-240 in CFRMF and Preparation for Absolute Fission Counting at $100 \mathrm{~kW}$, "contribution to Interlaboratory Reaction Rate Program 12th Progress Report, HEDL-TME 19-58, pp. NBS-57 to NBS-68 (1979).

7. R. C. Greenwood, et. a7, "Radiometric Reaction-Rate Measurements in CFRMF and BIG-10," in Proc. 2nd ASTM-EURATOM Symposium on Reactor Dosimetry, Palo Alto (1977), NUREG/CP-004, Vol. 3,1207 (1978).

8. R. A. Anderl and $Y$. D. Harker, "Measurement of the Integral Capture and Fission Cross Sections for ${ }^{2} 32$ Th in the CFRMF," in Proc. International Conference on Nuclear Cross Sections for Technology, Knoxville, Tennessee, October 22-26, 1979, NBS Special Publication 594, 475 (1980).

9. Y. D. Harker, R. A. Anderl, E. H. Turk, and N. C. Schroeder, "Integral Measurements for Higher Actinides in CFRMF," ibid, p 548.

10. R. A. Anderl and N. C. Schroeder, "Integral Capture and Fission Cross Sections for ${ }^{241}$ Am and ${ }^{243}$ Am in the CFRMF," to be published as US DOE Repnrt EGG-PHYS-5691, Idaho National Engineering Laboratory (1982).

11. W. N. McElroy and L. S. Kellogg, Nuc. Tech 25, 180 (1975).

12. J. A. Grundl and C. M. Eisenhauer, "Fission Spectrum Neutrons for Cross-Section Validation and Neutron Flux Transfer," in Proc. Conf. on Nuclear Cross Sections and Technology, NBS Special Publication 425 , Vol. I, p. 270 (1975).

13. R. A. Ander7, D. A. Millsap, JW Rogers, Y. D. Harker, "Addendum to Integral Data Testing Report for ENDF/B-V Dosimeter Cross Stctions," US DOE Report EGG-PHYS-5668, Idaho National Engineering Laboratory (1982).

14. R. A. Anderl, "INEL Integral Data-Testing Report for ENDF/B-V FissionProduct and Actinide Cross Sections," US DOE Report EGG-PHYS-5406, Idaho Mational Engineering Laboratory (Apri1, 1980).

15. F. Schmittroth, "FERRET Data Analys is Code," US DOE Report HEDL-TME 79-40, Hanford Engineering Development Laboratory (1971).

16. Private communication from F. Schmittroth, Hanford Engineering Development Laboratory (February, 1982).

17. G. T. Baldwin and G. F. Knoll, "Absolute Measurement of the Cross Section for 23-keV Neutron Activation of Thorium, "this meeting.

18. R. A. Anderl, N. C. Schroeder and Y. D. Harker, "Fast Integral Cross Sections for $241 \mathrm{Am}$ and $243 \mathrm{Am}$," contributed paper to be presented at the ANS Topica? Meeting on Advances in Reactor Physics and Core Thermal Hydrautics, Kiamesha Lake, New York, September 22-24, 1982.

19. K. Wisshak, et. al, "Fast Neutron Capture in Actinide Isotopes: Recent Results from Karlsruhe," this meeting.

20. L. W. Weston, "Review of Fast-Neutron Capture Cross Sections of the Higher Plutonium I sotopes and $241_{\mathrm{Am}}$, this meeting. 
Table 1. Sumulary of Integral Measurements and Integral Test Results for Actinide Reactions in the CFRMF

\begin{tabular}{|c|c|c|c|c|c|c|c|c|}
\hline Reaction & $\begin{array}{c}\text { Experiment } \\
\text { Type } \\
\end{array}$ & Reference & $\frac{\text { Inteyral }}{\text { Measured }}$ & $\begin{array}{c}\text { Cross Section (mb) } \\
\text { Calculated }\end{array}$ & $\underline{C} / \mathrm{M}$ & V/IV & $\frac{95 \% \text { Respon }}{E_{L}(\mathrm{MeV})}$ & $\begin{array}{l}\text { Ise Range } \\
\mathrm{E}_{\mathrm{u}}(\mathrm{MeV})\end{array}$ \\
\hline${ }^{232} \operatorname{Th}(n, f)$ & $\gamma$-Spec & 8 & $19.6(5.2)$ & $19.14(7.5,5)$ & $0.98(9)$ & 1.06 & 1.2 & 8.3 \\
\hline$(n, \gamma)$ & Y-Spec & 8 & $290.8(3.8)$ & $252.0(1.5,11)$ & $0.87(4.1)$ & 0.91 & $6.8 E-5$ & 1.6 \\
\hline${ }^{235} U(n, f)$ & FC & 5 & $1538 .(3.1)$ & $1552 .(0.5,2)$ & $1.01(3.1)$ & 0.99 & $2.2 E-4$ & 3.6 \\
\hline${ }^{23} u(n, f)$ & FC & 5 & $75.1(3.3)$ & $79.59(7.4,4)$ & $1.00(8)$ & 1.00 & 1.1 & 7.8 \\
\hline$(n, \gamma)$ & $\gamma$-Spec & 7 & $217 .(3.7)$ & $216.8(1.6,5)$ & $1.00(4)$ & 0.99 & $8.7 E-5$ & 1.4 \\
\hline${ }^{237} \mathrm{~Np}(\mathrm{n}, \mathrm{f})$ & $\mathrm{FC}$ & 5 & $548 .(3.3)$ & $606.1(3.6,10)$ & $1.11(5)$ & 1.01 & 0.3 & 5.8 \\
\hline${ }^{239} 9_{\mathrm{Pu}(n, f)}$ & FC & 5 & $1792 .(2.2)$ & $1773 .(0.2,2)$ & $0.99(2.2)$ & 1.00 & $2.4 E-4$ & 4.1 \\
\hline${ }^{240} \mathrm{Pu}(n, f)$ & DFC & 6 & $573 .(3.8)$ & $623.4(6,-)$ & $1.08(7)$ & 1.01 & $9.0 \mathrm{E}-\hat{\mathrm{C}}$ & 5.6 \\
\hline${ }^{242} \mathrm{Pu}(\mathrm{n}, \mathrm{f})$ & $\gamma$-Spec & 8 & $557 .(10)$ & $477.1(6,-)$ & $0.86(12)$ & 0.96 & 0.3 & 5.9 \\
\hline$(n, Y)$ & $\gamma$-Spec & 8 & $146 .(15)$ & $266.1(2,-)$ & $1.82(15)$ & 1.18 & $5.2 E-5$ & 1.3 \\
\hline${ }^{241}$ Anil $(n, f)$ & $\gamma$-Spec & 9 & $450 .(6.2)$ & $526.4(6,-)$ & $1.17(9)$ & 1.07 & 0.3 & 6.2 \\
\hline$(n, \gamma)$ & IDAS & 9 & $1550 .(3.5)$ & $1098 .(n,-)$ & $0.71(4)$ & 1.69 & $1.2 E-4$ & 1.0 \\
\hline${ }^{243} \operatorname{Am}(n, f)$ & $\curlyvee$-Spec & 9 & $353 .(6.1)$ & $419.8(6,-)$ & $1.19(9)$ & 1.21 & 0.4 & 6.6 \\
\hline$(n, Y)$ & $\gamma$-Spec & 9 & $895 .(4.8)$ & $583.6(2,-)$ & $0.65(5 j$ & 1.30 & $7.8 E-5$ & 0.7 \\
\hline
\end{tabular}

a. Ninty-five percent of the reaction response in the CFRMF is between the lower eneryy, $E_{L}$, and the upper energy $E_{u^{\circ}}$ 

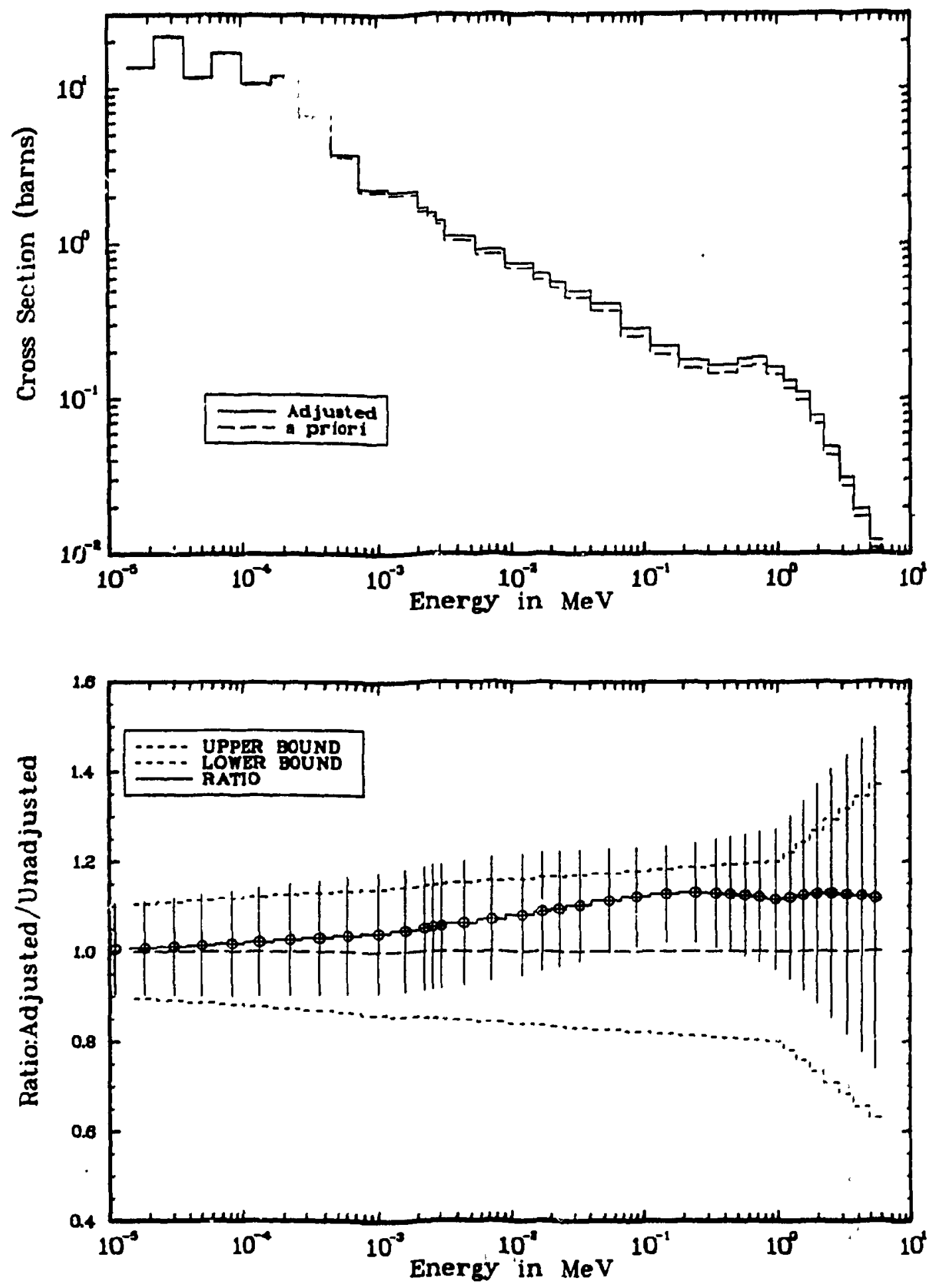

Figure 1. Comparison of adjusted and unadjusted cross sections for ${ }^{232} \mathrm{Th}(n, \gamma)$. In the lower half of the figure, input crosssection uncertainties are indicated by upper and lower bounds and adjusted uncertainties are indicated by vertical lines through the group mid-energy points. 

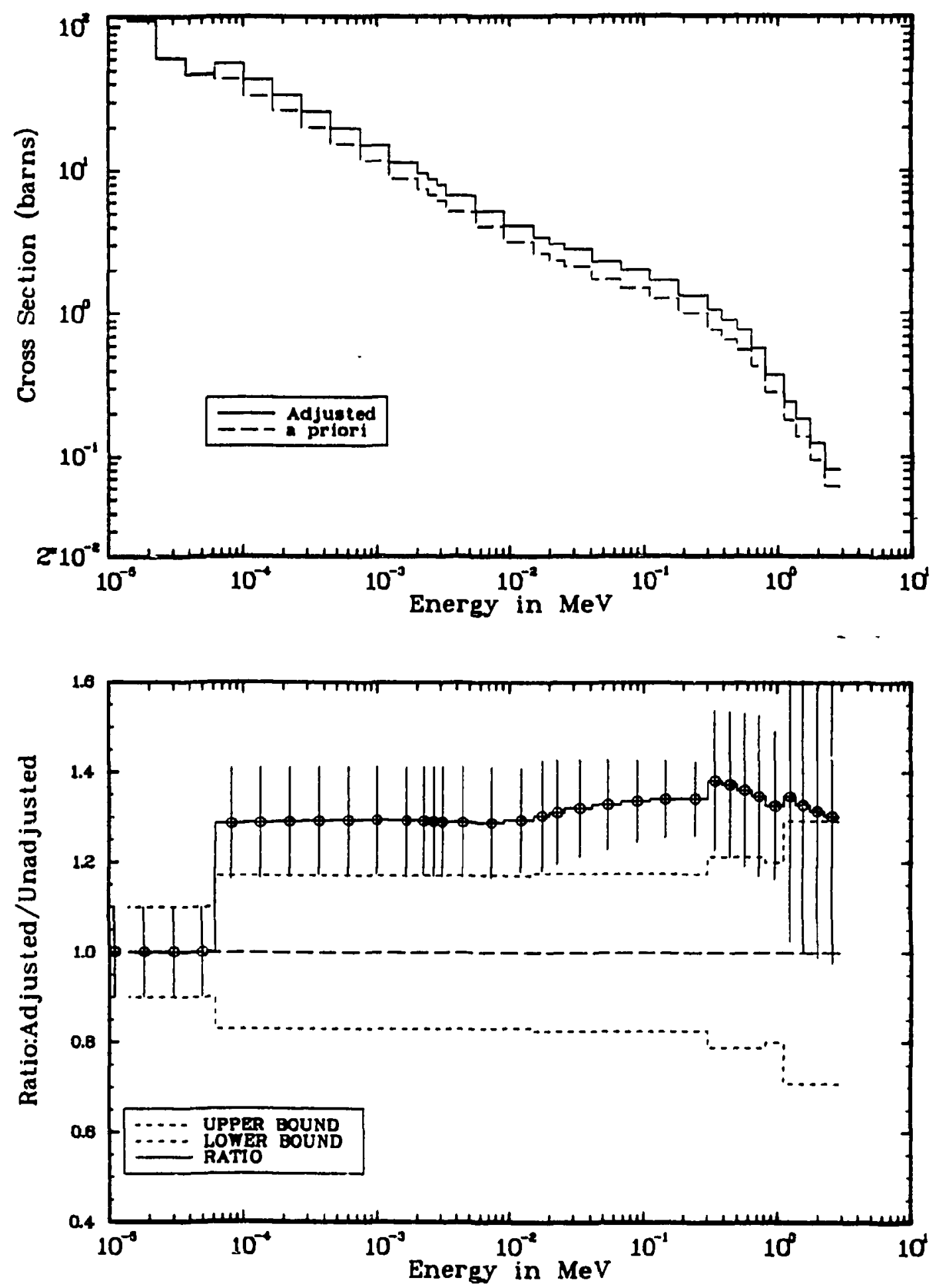

Figure 2. Comparison of adjusted and unadjusted cross sections for $241 \mathrm{Am}(n, \gamma)$. In the lower half of the figure, input crosssection uncertainties are indicated by upper and lower bounds and adjusted uncertainties are indicated by vertical. lines: through the group mid-energy points. 

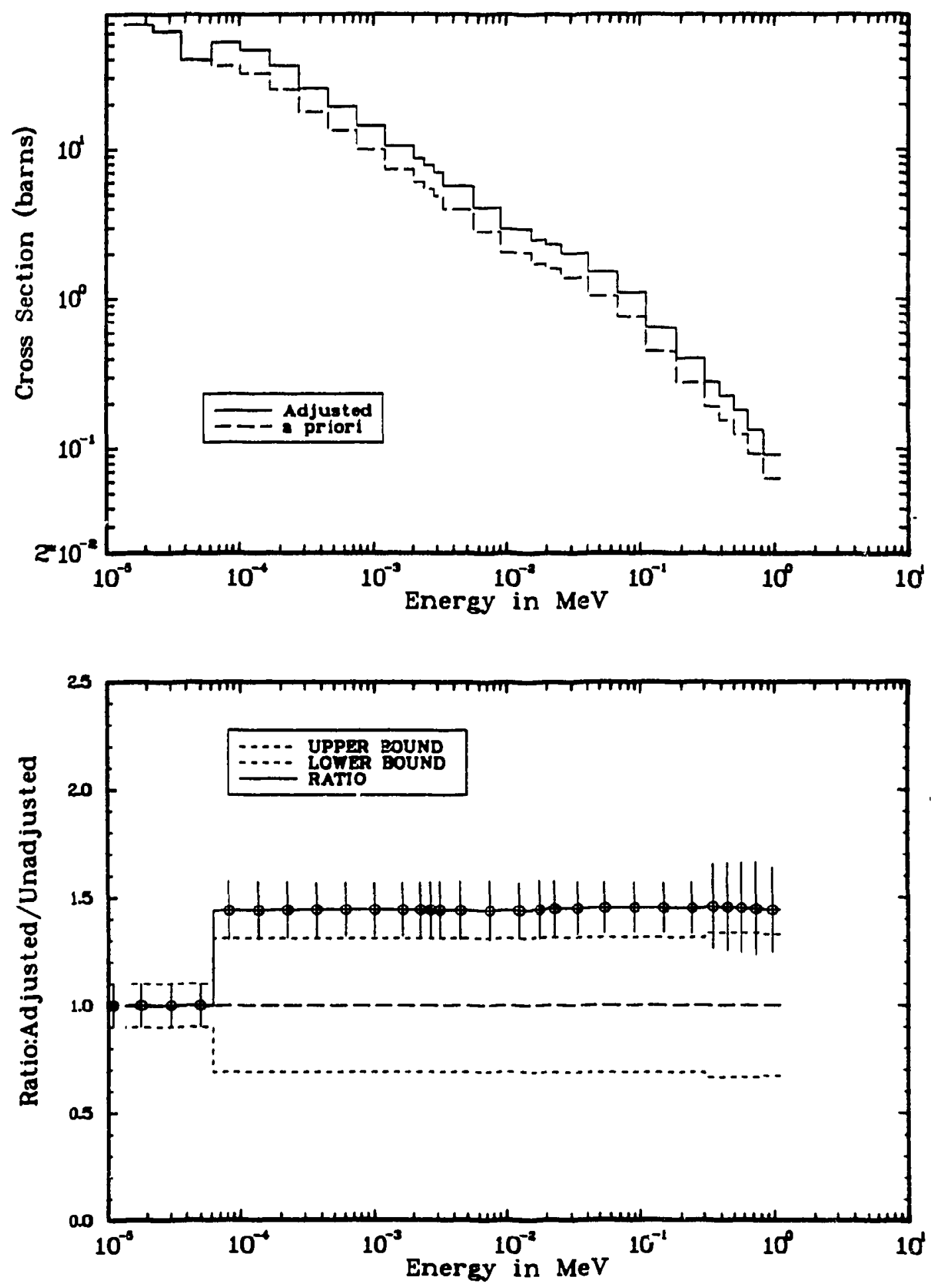

Figure 3. Comparison of adjusted and unadjusted cross sections for $243 \mathrm{Am}(n, \gamma)$. In the lower half of the figure, input cross section uncertainties are indicated by upper and lower bounds and adjusted uncertainties are indicated by vertical lines through the grnup mid-energy points. 